\title{
Evaluation Study of Boundary and Depth of the Soil Structure for Geotechnical Site Investigation using MASW
}

\author{
A. Arisona ${ }^{1,2}$, Mohd.Nawawi ${ }^{1}$, Amin E. Khalil ${ }^{1,3}$, \\ U.K Nuraddeen ${ }^{1}$, Mohd. Hariri ${ }^{1}$, M.A. Fathi ${ }^{1}$ \\ ${ }^{1}$ Geophysics program, School of Physics, Universiti Sains Malaysia. \\ ${ }^{2}$ Geophysical Department, Haluoleo University, Kendari,Indonesia. \\ ${ }^{3}$ Geology Dept., Faculty of Science, Helwan University, Egypt, Mesir.
}

* Corresponding author : arisona1972@hotmail.com

Tel.: +60164607608

Received: Feb 1, 2017. Revised : 15 Feb 2017, Accepted: Feb 20, 2017, Published: 1 March 2017. DOI: 10.24273/jgeet.2017.2.1.21

Abstract

This study reviews the correlation between the experimental Rayleigh dispersion curve and the Vp \& Vs ground model versus depth. Six samples of stations A , B , C, D , E and F were used in the experiment.The geophone spacing used was set $1 \mathrm{~m}$ and total length of each line was $23 \mathrm{~m}$. The result shows positive significance (best fit) of R2 that ranges from 0.80 to 0.90. The fk (frequency-wave number method) dispersion curves analysis confirmed that the soil structure investigated is divided into three zones: (1) Unsaturated soil zone (clay soil), in which the layer is dominated by soil with typically alluvial clayey silt and sand. The $V p$ ranges from $240 \mathrm{~m} / \mathrm{s}$ to $255 \mathrm{~m} / \mathrm{s}$ at a depth of 2 to $8 \mathrm{~m}$. (2) The intermediate zone (stiff soil), in which the layer is dominated by sand, silt, clayey sand, sandy clay and clay of low plasticity. This structure is interpreted as partially saturated soil zone, the soil is typically very dense. It contains soft rock typically fill with cobble, sand, slight gravel and highly weathered at depth of 18 to $30 \mathrm{~m}$ with Vp of 255 to $300 \mathrm{~m} / \mathrm{s}$. (3) Saturated soil zone at a depth of 8 to $18 \mathrm{~m}$ with $\mathrm{Vp}$ of 300 to $390 \mathrm{~m} / \mathrm{s}$. There is a very good agreement between wave-number (k) and phase velocity (Vw) produced. Both the two parameters shows similar pattern in the topsoil and subsurface layer, which constitute boundary field of soil structure. Moreover, relationship between phase velocity versus wave-length shows best fit of model from inversion with measured value (observed) in implementation of the boundary and depth of each layer.

Keywords: MASW, dispersion Curve, Phase velocity, Wave number, Wavelength.

\section{Introduction}

Multichannel Analysis of Surface Wave (MASW) survey is gaining popularity in geophysical/ geotechnical investigation due to the fact that it is non-destructive and provides accurate means of site characterization. It has been applied to delineate boundaries and depth of the target structure for geotechnical site investigation. Blake (2009) used MASW to define the velocity of the structure and depth to bedrock. This survey gives information of sub surface structure, thickness of layers, wave velocity of a body, and soil amplification parameters like Vs30; all of which are important in earthquake engineering. The utilization of MASW for soil characterization originates from the inherent nature of this kind of wave. Tran (2008) studied surface wave propagation along a free surface and associated motion, important information about the mechanical properties of the medium is revealed.

The objective of this study is to characterize the boundary and depth of the soil structure using MASW technique that substitute core drilling of sample (which is very expensive to perform), so necessitating geophysical technique as alternative means. Basically, geophysical method involve measuring the physical properties of the ground (or structure) and determining variations or 'anomalies' in the background readings (Keary, et al.,2002).

Furthermore, the occurrence of anomalies can indicate the presence of features or changes in a material composition (Keary, et al.,2002). Dey (2015) reveals that unlike conventional borehole sounding test, geophysical method is less expensive and it provides the benefit of precision to estimate the subsurface compression and shear wave velocity profile over a large area. It has been found to be better in some aspect compared to the other non-invasive methods such as the Ground Penetrating Radar (GPR) and Nuclear Magnetic Resonance (NMR) techniques. A significant application of geophysical method in geotechnical engineering practice is determination of boundary, depth layer and insitu characterization of soil (Grandjean, 2009 and Hiltunen et al., 2012). Critical analysis of the modeling observes whether geophysical signatures can characterize the physical properties that affect the saturation of soil. 
This analysis focuses on the dispersion of surface waves using MASW method (the fact that wavelengths with different frequencies travel at different speeds). The basic principle is quite simple, the various components (frequencies) of the seismic signal travel at a speed that depends on the characteristics of the medium (Dey, 2015). To determine accurate dispersion information, multichannel data processing methods are required to discriminate against noise and enhance Rayleigh wave signals (Tran, 2008 and Chik et al., 2011). The Pattern of the relantionship of the layers can be formulated mathematically as:

$k_{m}(\omega)=\frac{\omega}{V_{R_{m}}(\omega)}=\omega P_{m(\omega)}$

Where the wavenumber $(\mathrm{km})$ generated by equation (1) is inversely proportional to phase velocity $\left(V_{R m}\right)$ or equivalently proportional to the slowness $P_{m}(\omega)$. For a given frequency, surface waves have uniquely defined wavenumbers $k_{0}(f)$, $k_{1}(f), k_{2}(f)$ for different modes of propagation. In other words, the phase velocities $V_{R m}=\omega / k_{m}$ are fixed for a given frequency. The $\mathrm{f}-\mathrm{k}$ transform allows separation of the modes of surface waves by checking signals at different pairs of $\mathrm{f}-\mathrm{k}$.

The MASW method uses this dispersive property to estimate $P$ and $S$ wave velocities. It was reported by Roy (2013) that the MASW method has been developed with the assumption that the subsurface is vertically heterogeneous and laterally homogeneous (i.e. a layer-cakemodel). The MASW used phase information of high-frequency Rayleigh waves recorded on vertical component geophones to determine near-surface S-wave velocities (Tran, 2008). The differences between MASW results and direct borehole measurements are approximately $15 \%$ or less. Studies show that inversion with higher modes and the fundamental mode simultaneously can increase model resolution and depth of investigation (Xia, 2014).

The maximum depth of penetration is determined by the longest wavelength of the surface waves. The longest wavelengths generated depend on the impact power of the source and physical properties of the subsurface (Pei ,2007). The greater the impact power, the longer the wavelength and the greater will be the depth of penetration. Although the impact of the source such as a heavy weight drop can generate a longer wavelength of surface waves, they are very costly and not convenient for field operation. Therefore, a controlled type of seismic source such as a sledge hammer is used in an active survey (Dey, 2015).

The penetration depth of Rayleigh waves is about 0.4 times the longest wavelength (Schuler, 2008). Therefore, the depth of investigation can be estimated by using the dispersion curve. Since wavelength is equal to velocity divided by frequency we can estimate the depth of penetration using the equations:

$$
\mathrm{D}=0.4 \sqrt{\left[\frac{\mathrm{V}_{\mathrm{r}}}{\mathrm{f}}\right]^{2}} \quad \text { and } \quad \lambda=\frac{\mathrm{V}_{\mathrm{r}}}{\mathrm{f}}
$$

Where $\lambda$ is wavelength $(m) ; D$ is depth of penetration $(\mathrm{m}), \mathrm{Vr}$ is Rayleigh wave velocity $(\mathrm{m} / \mathrm{sec})$ and $\mathrm{f}$ is Frequency $(\mathrm{Hz})$.

On the other hand, the dispersion curve is an interpretation of the different modes or harmonics of the surface wave as it propagates through a given media.

\section{Site description and geology}

The study was carried out in Pedas, Negeri Sembilan, Peninsular Malaysia (Figure 1). This area has a distinctive and unique geology than the surrounding areas because of the presence of hot springs. Hot spring is allegedly originates from the host rock, it is then migrated through the grounds and surrounding rock (limestone and sandstone) impregnated.

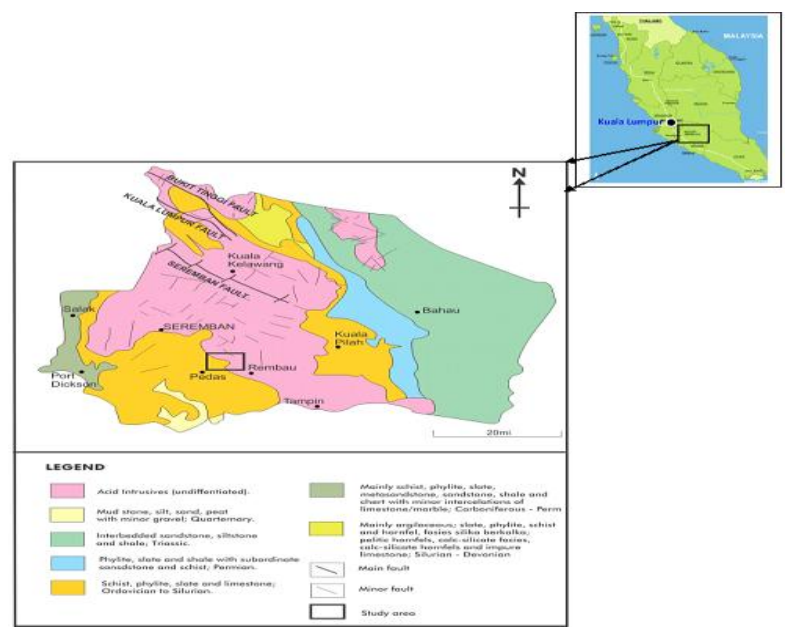

Figure 1. Geology Map of Negeri Sembilan, Peninsular Malaysia (modified from JMG, 2014). The location of the study areas in the Geological map is showing presence of Hot Spring.

Pedas is located in the vicinity of Seremban Fault Zone that lies within the West Belt Granite intrusion. Alexander (1968) revealed that the structural geology in the igneous rock of Pedas area was dominated by granites with typically medium to coarse grained rocks, often porphyritic. Based on the Negeri Sembilan geological map, the location of site investigation is part of the main fault zone that is controlled by meta-sediment and granite rocks. Soil structure around hot spring with typically saturated soil. It comprises of sandstone, silty sandy gravel, and granite (bedrock), as was confirmed by Hamizah (2016) on the study of Electrical resistivity imaging (2D and 3D) and Geochemical study in the hot spring area in Pedas.

Soil type depends on the parent rock type of the basin, although variations may occur over small distance due to differences in local condition. The bed rock in the study area is overlain by alluvial deposits of red and yellow lateritic clay, sand and 
gravel. The alluvium is quite deep in certain areas especially along the hills due to aggregation and tin mining activities. The alluvial deposits, especially along the rivers are composed of gray clay and peat. More areas under laterite are found along the southwestern coast of the state (Nather Khan and Mustafa, 2010). Geological genesis of hot spring formation at Pedas is still studied by experts.

\section{Experimental Work}

The MASW measurements were carried out along 52 stations in the study area. The stations were selected based on data picking and frequencies to obtain best a curve fit. In this study, six samples were collected for use in MASW dispersion Inversion.

Figure 2 shows the arrangement of 24 channels geophones using the spacing of $5 \mathrm{~m}$ and set $1 \mathrm{~m}$ inter-distance is used for recording data and the total length was $23 \mathrm{~m}$. The energy source was set at $15 \mathrm{~m}$ offsets. The data were recorded using the sampling rate of $1 \mathrm{~ms}$. The data were recorded by Commercial Instruments (TERRA LOOK MK-8). There are two main procedure involve in MASW data processing technique adopted in this study : generation of dispersion curves (frequency vs. phase velocity plots), and inversion of dispersion curves to estimate S-wave velocities (Roy , 2013).

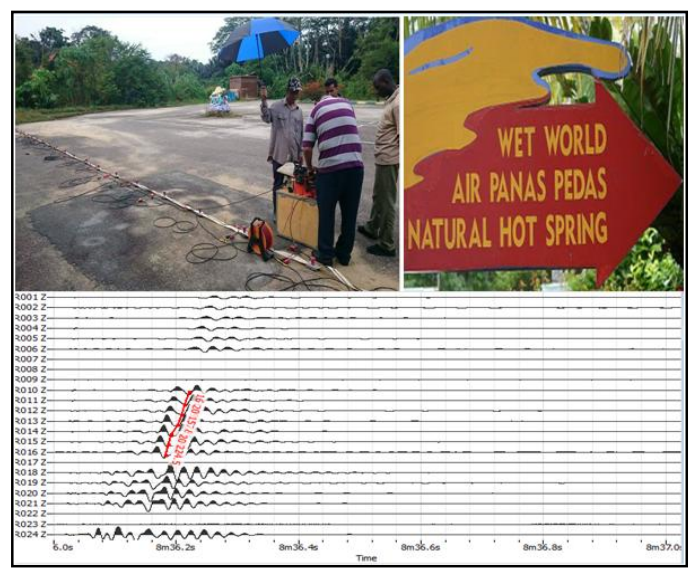

Figure 2. MASW field setup and recorded data on 24 channel at the site

The theoretical dispersion curve is calculated from random parameters given by the NA (forward problem) and then the number of layers to invert is chosen. There are four parameters to invert: P-wave velocity $(\mathrm{Vp})$, Poisson ratio, S-wave velocity (Vs) and depth. Density was held constant at 2000 $\mathrm{kg} / \mathrm{m} 3$ (Table 1). It was found that the choice of $\mathrm{Vp}$ did not have much influence on the inversion process.

Through trial-and-error, a three-layer model appeared to provide best fit to the data set. Finally, the misfit between the theoretical dispersion curve and recorded data is evaluated.

The depth to soil layer value is determined for each site as the depth to the boundary of layer 1 and layer 2 . The best fit model of dispersion inversion for this study comprises of 3 layers (as seen in Table 1 ). Layer 1 and 2 of the model fit to the geological setting of soil structure around hot spring with typically saturated soil, comprises of sandstone, silty sandy gravel, and granite (bedrock).

All model inversions were conducted using Geopsypack win32 v. 2.10.1. A neighbourhood algorithm applied in Dinver software is used to invert $\mathrm{Vs}$ and $\mathrm{Vp}$ profiles. It's done by trying different models and finding the misfit of each one compared with the experimental dispersion curve.

Active-source experiments are processed with a fk technique. At the same location, the various shots available are stacked together with time. The various shot locations are combined to get standard deviations on dispersion curves usually picked without error estimates (Wathelet, 2014). These uncertainties are analogous to those derived from ambient vibrations (stationary in time viewed as a random variation of source locations).

\section{Result and Discussion}

Figure 3 shows that each dispersion curve have a chance in source effects of surface waves. The signal to noise ratio is a measure of high amplitude wave energy at a given frequency, which assists in dispersion curve picking. The picking is automatically adjusted to the maximized the fk output.

By selecting the lowest frequency on dispersion curve at six stations (Figure 3), this survey estimated approximately 15 to $59 \mathrm{~m}$ deep accurately (based on the equation 2) and the estimated results are shown in Table 2.

Figures $4 a$ and $4 b$ shows linearity dispersion curve (relationship wave number $\mathrm{k}$ with depth $\mathrm{d}$ and phase velocity $\mathrm{Vw}$ ), which caused by the homogeneity of the material beneath the surface, both the profiles above shows similar patterns. This can be observed when we compare the upper soil layers (top soil) with lower layer (bedrock). In addition, the curve which gives the best fit to the measured data can provides information regarding maximum depth, and also interpretation at boundary inter-layers.

Moreover, both profiles showed a significant correlation with R2 of each 0.954 and 0.939 , in which the curve gives the best fit to the measured data to determine the boundary and depth of each layers. Moreover, it indicates that the similarity of material, specifically a soils layer around the survey area. The dependence phase velocity and depth distribution on wavenumber has been conducted by Chik et al. (2011). It shows the linearity of frequency and phase velocity versuswave-number relationship. The theoretical dispersion reveals consistent shear wave velocity profile in the evaluation of near surface soil properties. Specifically to implement a wide variety of geotechnical investigations, including pavements, solid waste landfills, and sea beds profile. 
Tablel . Ranges used in parameters for the MASW dispersion Inversion

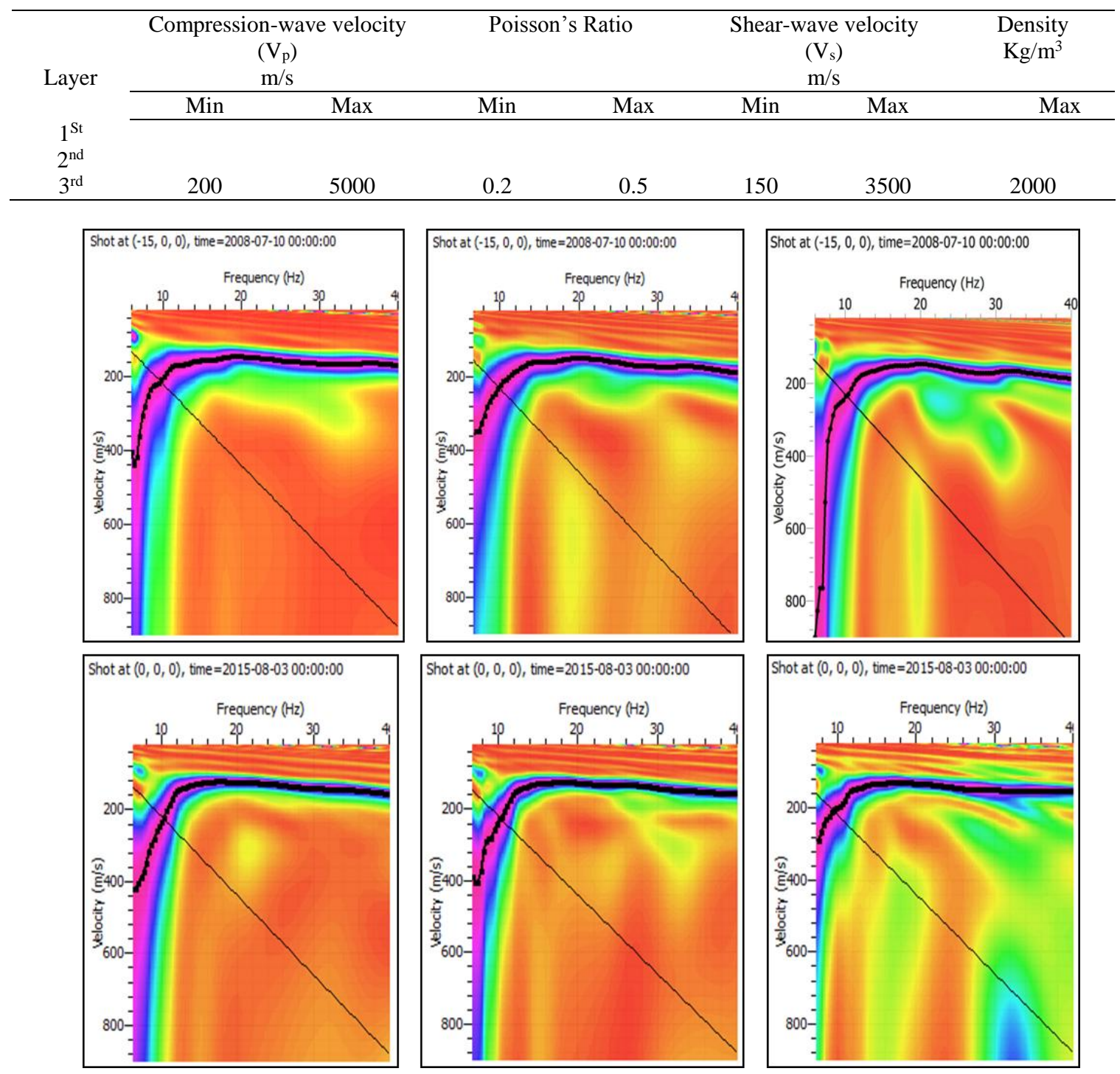

Figure 3. Dispersion curves from stations A, B, C, D, E and F with a $15 \mathrm{~m}$ source offset

Table 2 Estimates of Soil Structure Depth

\begin{tabular}{lcccccc}
\hline Station & A & B & C & D & E & F \\
\hline Frequency $(\mathrm{Hz})$ & 6.16 & 7.29 & 6.07 & 6.56 & 7.3 & 7.4 \\
Velocity $(\mathrm{m} / \mathrm{s})$ & 440.18 & 350.88 & 900 & 420.36 & 471.89 & 285.59 \\
Depth $(\mathrm{m})$ & 28.58 & 19.25 & 59.31 & 25.63 & 25.86 & 15.44 \\
\hline
\end{tabular}

Table 3. Regression analysis of dependence of phase velocity $\left(V_{\omega} \mathrm{m} / \mathrm{s}\right)$ on wave length $(\lambda \mathrm{m})$, linear model ( $95 \%$ higher confidence level ).

\begin{tabular}{cccc}
\hline Station label & $\begin{array}{c}\text { Correlation Coefficient } \\
\left(* \mathrm{R}^{2}\right)\end{array}$ & Equation of the fitted model & $\begin{array}{c}\text { Standar Errors of estimate } \\
(\%)\end{array}$ \\
\hline A & 0.918 & $\lambda=0.221 \mathrm{~V}_{\omega}-27.57$ & 3.29 \\
$\mathrm{~B}$ & 0.904 & $\lambda=0.227 \mathrm{~V}_{\omega}-30.04$ & 3.81 \\
$\mathrm{C}$ & 0.867 & $\lambda=0.185 \mathrm{~V}_{\omega^{-}}-23.13$ & 3.82 \\
$\mathrm{D}$ & 0.855 & $\lambda=0.220 \mathrm{~V}_{\omega}-24.70$ & 3.36 \\
$\mathrm{E}$ & 0.915 & $\lambda=0.177 \mathrm{~V}_{\omega}-18.27$ & 3.14 \\
$\mathrm{~F}$ & 0.945 & $\lambda=0.187 \mathrm{~V}_{\omega^{-}}-19.37$ & 3.10 \\
\hline
\end{tabular}

*Significantly level is 0.05 


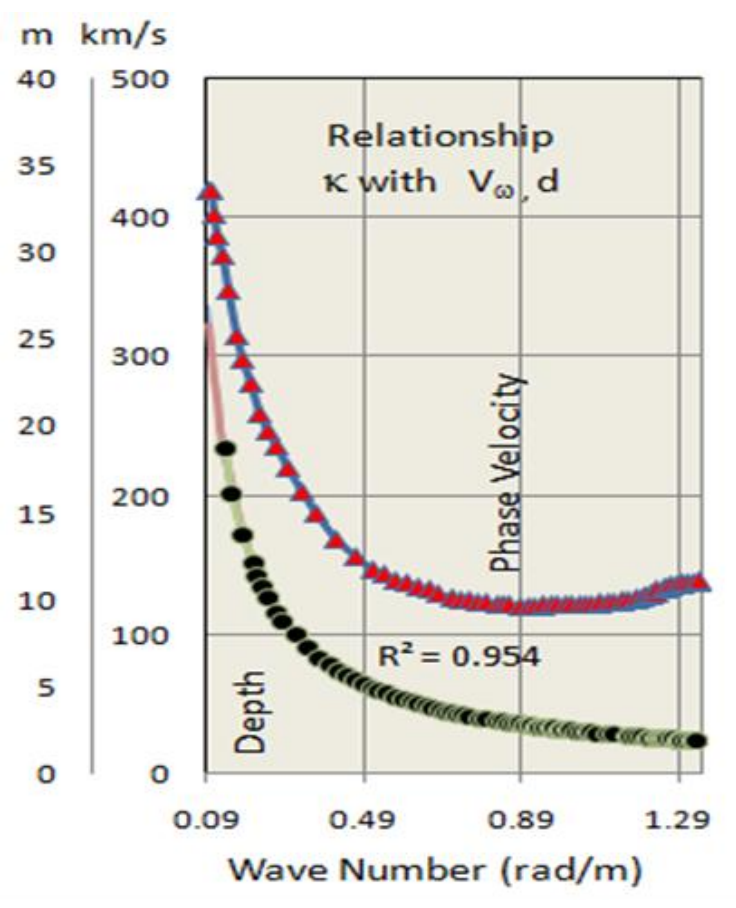

a

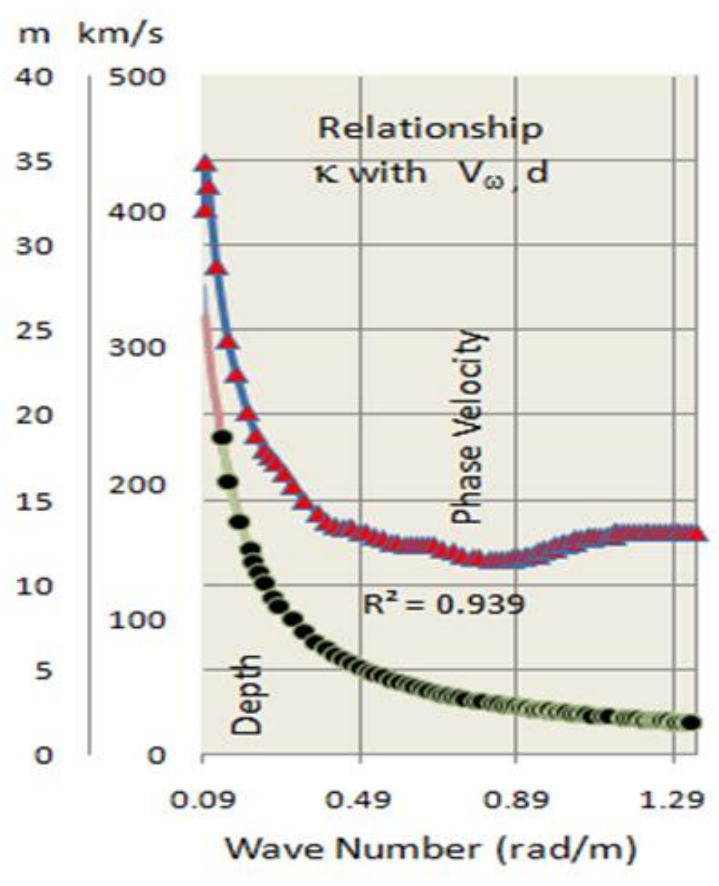

b

Figure 4. Combined raw dispersion curves by active fk (requency-wavenumber method) MASW techniques that was adopted from six station at site test a) Stations A,B and C b) Stations D, E and F. Plotted graph have extracted result from Figure 4 by using equation 1.

Figures $5 a, 5 b$ and $5 c$ shows fk dispersion curve relationship between phase velocity versus frequency and $\mathrm{Vp} \& \mathrm{Vs}$ versus depth. The models have a misfit lower than 0.4 , in which colour code shows the misfit of each model.

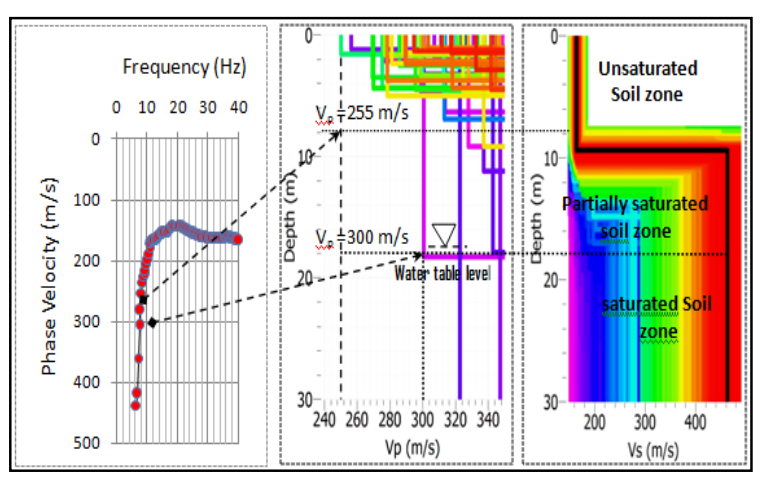

Figure 5. Joint inversion of FK dispersion curve analysis. (a) Extracted dispersion curve by phase velocity versus frequency at station $A$ ( as a comparison for estimates of depth and boundary / layer). (b and c). A view of the parameter space using the $\mathrm{Vp}$ and $\mathrm{Vs}$ profiles for two layer of soil synthetic data. Soil zone characterized based on Figure $1 b$.

The black line represents the shear-wave velocity model with minimum misfit.

Based on the refraction survey, dispersion curve (Figure 5a) shows the wave velocity range from 255 $\mathrm{m} / \mathrm{s}$ to $300 \mathrm{~m} / \mathrm{s}$ in the unsaturated soil zone at the depth of $8 \mathrm{~m}$ (water table level). Below the water table, the wave velocity continues to decrease till the depth of $18.0 \mathrm{~m}$, due to the effect of critically refracted waves. In the transition zone which is located below the water table, the velocity refers to an apparent velocity as was studied by Godio et al. (2010). The data in joint inversion of $\mathrm{fk}$ analysis shows three different soil zones : the upper part of the unsaturated soil zone at a depth of 2 to $8 \mathrm{~m}$ with Vp of 240 to $255 \mathrm{~m} / \mathrm{s}$, saturated soil zone at a depth of 8 to $18 \mathrm{~m}$ with $\mathrm{Vp}$ of 255 to $300 \mathrm{~m} / \mathrm{s}$ and in the intermediate zones (estimated as partially saturated soil zone) at a depth of 18 to $30 \mathrm{~m}$ with $\mathrm{Vp}$ of 300 to $390 \mathrm{~m} / \mathrm{s}$. In intermediate zone the response is very sensitive to different saturation conditions due to the groundwater fluctuation and the different distribution of the water below the water table level.

The model (Figure 5b) shows a constant layer for at least 2 meters deep with phase velocity $(\mathrm{Vp})$ of $255 \mathrm{~m} / \mathrm{s}$. In addition, Figure 5c agrees with a constant first layer up to around 8 meters deep. An increase in the depth of the shear wave velocity dispersion curves, particularly at a depth of 8 meters is caused by the presence of water table level and solid layers. Cross-section in Figure 5b shows overlapping of profile lines, this is due to noise interference around the survey area.

The two layers for $\mathrm{P}$ - and $\mathrm{S}$-wave velocities (Figures 6) of the inverted profile fit the model indicated by red colours. The possible parameter range is indicated by the region that is covered by models. The corresponding depth models are plotted in Figures 5 and 6 . The compressional wave velocities reach $500 \mathrm{~m} / \mathrm{s}$ to $2000 \mathrm{~m} / \mathrm{s}$ with a velocity at depths of $20 \mathrm{~m}$. Discontinuity zone is found at about $30 \mathrm{~m}$ deep. While, Shear wave vel ocities range from $200 \mathrm{~m} / \mathrm{s}$ to $600 \mathrm{~m} / \mathrm{s}$ and as well as at depths of 
approximately $20 \mathrm{~m}$ to $30 \mathrm{~m}$, this is interpreted as a discontinuity zone. At depth of $30 \mathrm{~m}$ up to lower layer shows constant velocity, either Vp or Vs. These indicates that both $\mathrm{Vp}$ and $\mathrm{Vs}$ profiles has materials of homogeneities at depth down of $30 \mathrm{~m}$.

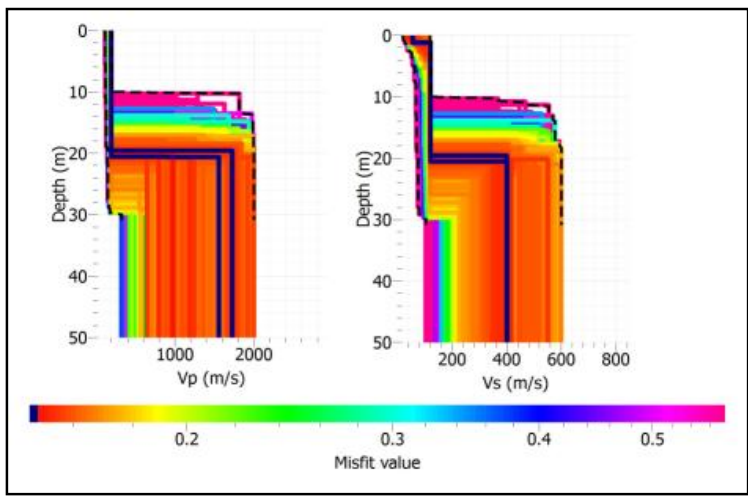

Figure 6. Depth against $\mathrm{Vp}$ and $\mathrm{Vs}$ profile with best misfit scale thatwas obtained in station D. The black line indicates the reference model (true dispersion curve) used as target curve inthe inversion process. The corresponding depth of models are plotted, the maximum depth is $50 \mathrm{~m}$.

Figure $7 \mathrm{a}$ and $7 \mathrm{~b}$ shows Joint inversion of slowness and ellipticity H/V (Slowness indicates frequency dependent group and phase velocity) and ellipticity curves are then simultaneously inverted to get the shear wave velocities. Extracted ellipticities provided information within the frequency band from 6 to $40 \mathrm{~Hz}$, shear-wave velocities are better constrained over larger depths than by using inversion of dispersion curve alone. However, even though such joint inversion provides the general shape of shear-wave velocity structure within sediments, bedrock depth is not constrained. In addition, the true ellipticity may also contain a smooth peak in case of gradual increase of the velocity with depth.

Figure 7a shows slowness drastically increase with frequency, particularly at frequency of $20 \mathrm{~Hz}$. This relationship indicates the presence of lowervelocity layers overlying a zone with a significant velocity decrease with depth.

An additional contribution to the analysis can be provided by the inversion of the ellipticity curve obtained as the result of the seismic noise analysis by using the tool dinver available in Geopsy package. The important assumption of this technique is that the analyzed wave field is mainly characterized by Rayleigh waves.

The fundamental and first higher mode in Figure $7 \mathrm{~b}$ could be consistently explained with a common mode. Nguyen et al, 2009 opined that interpretation of the first higher mode is correct, since other associations to even higher modes could not be consistently fitted.

In several cases, relationships of $\bullet$ with $\mathrm{f}$ and $\mathrm{Vw}$ , generally is connected to deep penetration. As it was reported by Babuska and Cara (1991) that longer wavelengths penetrate deeper than shorter wavelengths for a given mode, generally exhibit greater phase velocity, and are more sensitive to the elastic properties of the deeper layer. Shorter wavelengths are sensitive to the physical properties of surficial layers. Correlation was conducted in the wavelength rather than frequency domain, because wavelength is related more closely to depth of interest (Martin and Diehl , 2004).

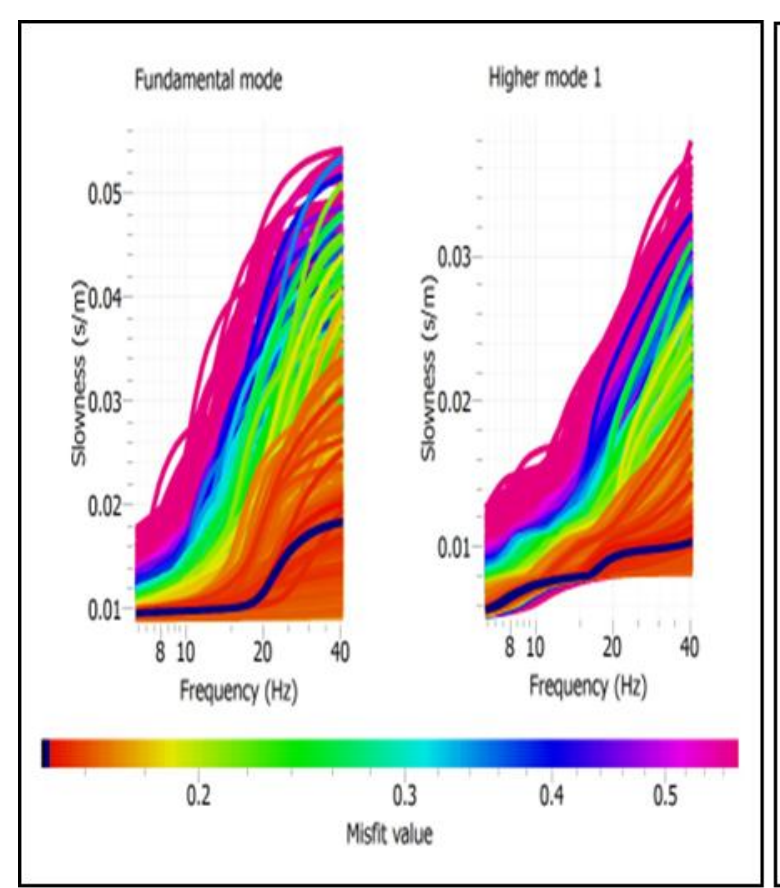

a

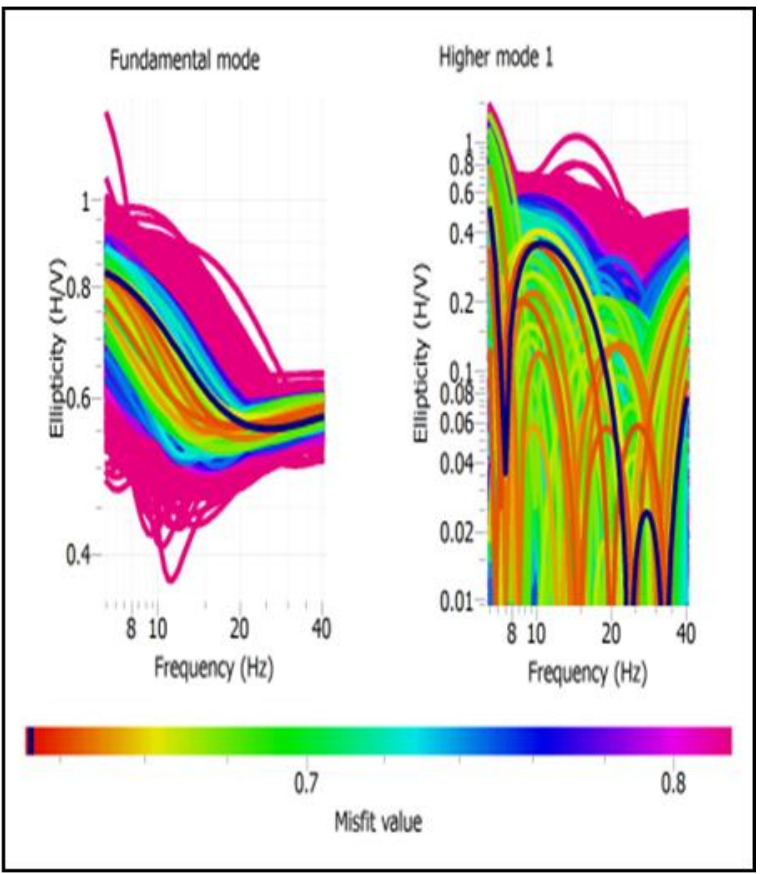

b

Figure 7 a) Contain the distribution curves for the fundamental Rayleigh mode and inversion results at array station $D$ b) of the ellipticity inversion that is adopted from station D. Observed curves used in the inversion are in black and the colour distinguishes the misfit value. Red and yellow colours represent optimal models with smallest misfits. 
Figure 8 shows the MASW Rayleigh dispersion curve obtained for stations $A$ to $F$ as function of the phase velocity and the wavelength; as the wavelength reflects more closely at the depth of penetration.

Curve of the model analysis in the phase velocity to wave length could be a suitable approach to estimate the geometric specifications of the soil layers, especially for the soil layers with a clear contrast between the sedimentary cover (Top soil) and bedrock. These allegation was very strong with the results of the correlation coefficient (R2) of a six stations by high significantly values which are $0.918,0.904,0.867,0.855,0.915$ and 0.945 , respectively. The results obtained from the regression analysis are in agreement with dispersion curve interpretation in test site with low percentage error as shows in Table 3. Moreover, the similarities between the equations in the studied sites are good evidence for the utilization of this method in the geotechnical site investigation.

Correlation between the experimental Rayleigh dispersion curve (phase velocity versus wavelength) and the Vs ground model (shear wave velocity versus depth) estimated from Rayleigh dispersion inversion was observed, and they confirm that these non-invasive techniques are useful in evaluating the Vs ground profile.

\section{Conclusion}

From the overview above, the MASW dispersion curves have successfully applied on characterizing and evaluating boundaries and depth that have significant implication in both geotechnical and engineering applications. Particularly in comparison with conventional drilling, it is cheap and provides the benefit of precision. It is suitable for estimating the subsurface shear and compression wave velocity profile over a large area.

The utilization of linear regression of two explicit empirical relationships for wavelength phase velocity and wave number versus depth and phase velocity has a good matching (best fit curve) and both relationships were recommended for correcting and estimation Rayleigh dispersion curve of soil structure due to the higher value of R2.

This confirms that relationship pattern of $\mathrm{fk}$ (frequency - wave number) dispersion curves is a good interpretation method for understanding the soil layers of the investigated area.
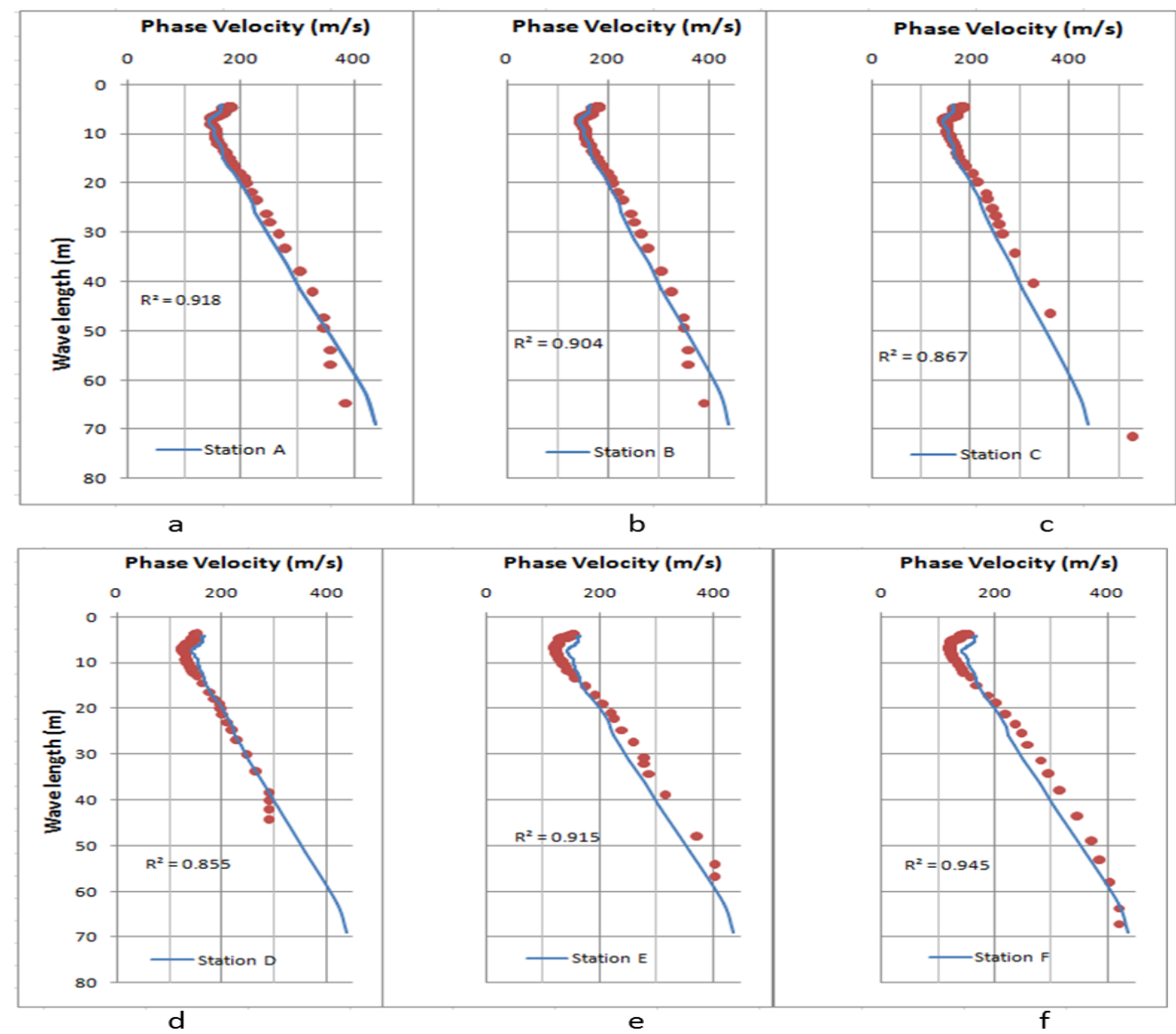

Figure 8. Representation of dispersion curve (a,b,c,d,e and $f)$ of the model analysis in the Phase Velocity Versus Wave Length obtained for stations A, B, C, D, E and F at test site in the study area (red dots are measured values and lines are best fit model) and correlation coefficients (R2) by each station. 


\section{Acknowledgements}

First of all we thank to the Directorate General of Higher Education (DGHE) of Indonesia who has giving us scholarship. The field support from colleague of Postgraduate student and technical staff of Geophysics Programme, School of Physics, Universiti Sains Malaysia is highly appreciated.

\section{References}

Alexander, J. B.,1968. The geology and mineral resources of the neighbourhood of Bentong, Pahang and adjoining portions of Selangor and Negeri Sembilan. Journal of Mal. Geol. Survey Mem. (NS) 8: 1-250.

Babusk,V. and Cara, M. ,1991. Seismic Anisotropy in the Earth , Modern Approaches in Geophysics, Volume 10 , ISBN: 978-94-010-5596-3, Springer Science \& Business Media.

Blake, D.R., 2009. Surface layer thickness and velocity determined using the Multi Channel Analysis ofSurface Waves (MASW) method compared with microtremor resonance analysis Federal Road, Greene County, Ohio, (thesis).

Chik,Z., Islam, T., and Taha, M.R., 2011. Implemented in awide variety of geotechnical investigations, including pavements, solid waste landfills, and sea beds profile, Tamkang Journal of Science and Engineering, Vol. 14, No. 2, pp. 107-114.
Dey,A.,2015.Subsurface Profiling using MASW: Aspects of Data Acquisition,Dispersion and Inversion Analyses (rep.).

https://www.researchgate.net/publication/2820029 61) (accessed 08.12.15)

Grandjean ,G.,2009. From geophysical parameters to soil characteristics (rep.).

http://eusoils.jrc.ec.europa.eu/public_path/DigisoilD2.1 (accessed 11.12.15)

Godio,A., Bastani, M., French, H., Bloem, E., Foti, S., Arato, A., and Pedersen, L. , 2010. Optimisitaion of geophysical field methods (rep.) http://www.bioforsk.no/ikbViewer/Content/71116/ version=1/SoilCAM_deliverable_D1.2 (accessed 07.09.16)

Hiltunen,D.R.,Hudyma,N.,Tran,K.T., and Sarno,A.I., 2012.Geophysical testing of rock and its relationthips to physical properties (rep.). http://www.fdot.gov/research/Completed_Proj/Su mmary SMO/FDOT BDK75 977-01 rpt(accessed 04.06.16)

Hamizah binti Mohamad, 2016. The study of Electrical resistivity imaging ( $2 \mathrm{D}$ and $3 \mathrm{D}$ ) and Geochemical in the hot spring area at Pedas (rep.)

Kearey, P., Brooks, M., and Hill , I., 2002. An Introduction to Geophysical Exploration , Third Edition, Blackwell Science Publications.

Martin,A.J. and Diehl,J.G.,2004. Practical experience using a simplified procedure to measure average ShearWave velocity to a depth of 30 meters $\left(V_{s} 30\right), 13^{\text {th }}$ world conference on Earthquake Engineering, Vancouver,B.C., Canada, August 1-6, 2004, Paper No. 952. 